\title{
Unique Foreign Body of the Pharynx- Touch Light Spring and Its Plastic Cover
}

Abiola Grace Adekanye ${ }^{1^{*}}$, Oku Oboko Oboko ${ }^{2}$, Umana Aniefon Ntuen ${ }^{1}$, Akintomide Akintunde Olusijibomi ${ }^{2}$, Kuni Joseph Iraskeb ${ }^{1}$, Offiong Mbora ${ }^{1}$ and Mgbe Robert Bassey 1

${ }^{1}$ Department of Otorhinolaryngology Head and Neck Surgery, University of Calabar Teaching Hospital (UCTH), Calabar, Cross River State, Nigeria

${ }^{2}$ Department of Anesthesiology and Intensive Care, UCTH, Calabar, Cross River State, Nigeria

${ }^{3}$ Department of Radiology, UCTH, Calabar, Cross River State, Nigeria

"Corresponding author: Abiola Grace Adekanye, Department of Otorhinolaryngology Head and Neck Surgery, UCTH, Tel: +2348050543605; E- mail: abiolaadekanye@yahoo.com

Received date: May 22, 2015; Accepted date: June 22, 2015; Published date: June 30, 2015

Copyright: ( 2015 Abiola Grace Adekanye et al. This is an open-access article distributed under the terms of the Creative Commons Attribution License, which permits unrestricted use, distribution, and reproduction in any medium, provided the original author and source are credited.

\begin{abstract}
Motorcycle riding is one of the transportation modalities especially in many rural communities in Nigeria. Many people have lost their lives through road traffic accidents (RTA) involving motorcycles especially when riding without a helmet. Motorcycle riding without headlight at night is a criminal offense and can result to RTA. We report a case of unique foreign body; plastic cover with its spring of two-cell touch light in the pharynx of a 45year old farmer who held touch light in his mouth as a source of light while riding motorcycle in the night. The Foreign body of this nature has not been reported in the literature.
\end{abstract}

Keywords: Unique foreign body; Touch light spring and plastic cover; Pharynx; Motorcycle accident

\section{Introduction}

Aero-digestive foreign body occurs mostly in children between the ages of 6 months to 5 years. It occurs less frequently in older children and adults. It is usually accidental but can result from deliberate ingestion by patients with mental illness [1], intellectual impairment, prisoners [2] and drug- mules/body -packers [3]. Objects that are commonly ingested by children include coins, small toys, pencils, pens and their tops, batteries, safety pins, needles and hairpins. In older children, food related items like fish and chicken bones are often ingested. In adults, denture or part of dentures can be accidentally swallowed [4]. The majority of ingested foreign bodies will pass safely through the gut and be passed with faeces [5], but some will cause damage to the gastrointestinal tract or become lodged [6]. Ingested foreign bodies may become impacted at oesophageal constrictions: at level of cricopharyngeal sphincter, broncho-aortic, left main bronchus, and diaphragmatic constriction. Impacted foreign bodies could cause life-threatening obstruction of upper GIT and respiratory tracts [7]. Patients may present with drooling of saliva, dysphagia, odynophagia, vomiting, chest pain, and neck pain $[8,9]$. Patients can also present with cough and stridor due to proximity of the upper airway and oesophagus [10].

Diagnosis of foreign body in the pharynx can be made from history, examination, radiological investigation and endoscopic examination. If the impacted foreign body is radiolucent, in the present of positive history, symptoms or clinical suspicion, endoscopic examination is suggested [11]. Diagnosis of radio-opaque foreign body ingestion does not pose a major problem. It is crucial to take a radiograph from the pharynx where the foreign body is most likely to become impacted, to the level of pylorus [12]. CT scan of the thorax/abdomen is highly useful for locating entrapped objects of various types and considered superior to plain X-ray imaging [5]. It is also an investigation of choice if there is reason to suspect perforation or abscess formation.
Treatment options of ingested foreign body vary from 'watchful waiting' to endoscopic extraction, balloon catheter extraction, fluoroscopic remover and laparotomy [8-10,13-15].

Our index patient had radio-opaque foreign body as shown on radiograph of soft tissue neck; lateral and antero-posterior views (Figure 1,2).

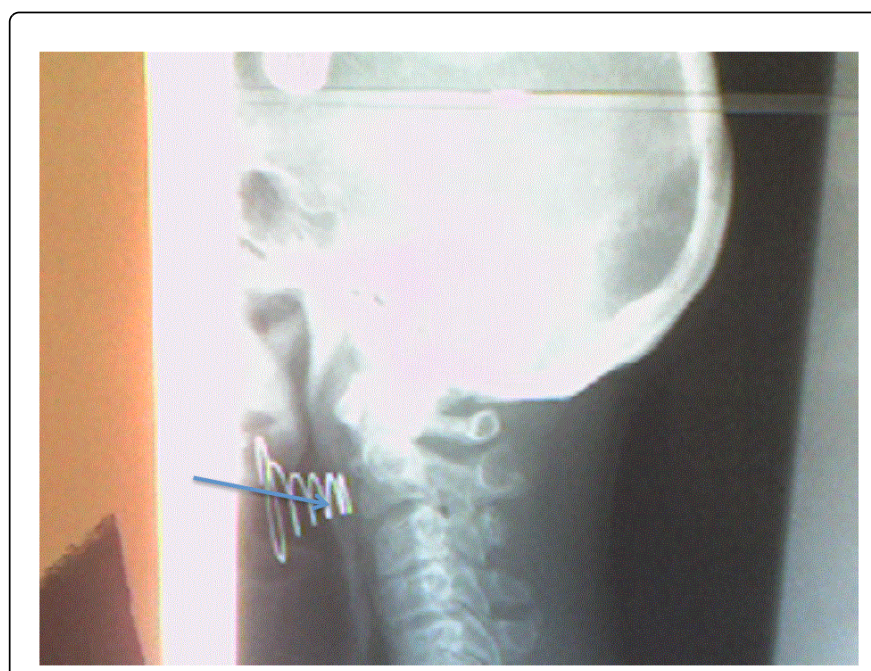

Figure 1: Lateral view of the neck radiograph shows a well-defined coiled metallic foreign body at the level of C2 between posterior aspect of tongue and epiglottis. 


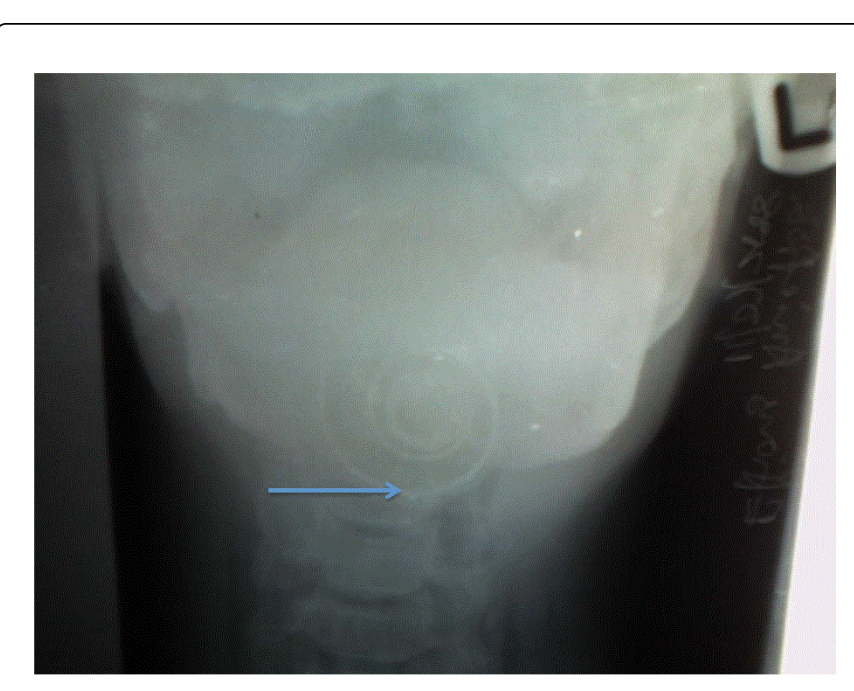

Figure 2: AP view of the neck radiograph shows the coiled metallic foreign body in the upper part of the neck overlapping the upper cervical vertebrae and mandible.

\section{Case Report}

A 45year old farmer referred from a rural health centre to the accident and emergency unit of our hospital with a 3-day history of throat pain, dysphagia to liquid and solid feeds and drooling of saliva following road traffic accident. He was riding a motorcycle without a headlamp in the night. He had a touch light held in his mouth to light his path and had head on collision with another motorcyclist. He lost consciousness immediately after the accident for 24 hours and also bled profusely from the mouth. There was an associated deep cut on the tongue, traumatic extraction of upper incisor teeth and chocking sensation whenever he swallowed. He also sustained an abrasion on the right knee. There was no associated nasal obstruction, epistaxis, dyspnoea, hoarseness, or stridor. No otological symptoms.

He had been resuscitated with intravenous fluids, the cut on the tongue sutured, wound on the knee dressed and antibiotics commenced at rural health centre.

Examination revealed a young man conscious and alert, warm to touch $\left(37^{\circ} \mathrm{C}\right)$, not in respiratory distress, moderately pale and drooling saliva. Oropharyngeal examination revealed bruises on the upper lip, loss of upper incisor teeth, bluish coloration of the tongue, stitches on distal third of tongue. The uvula had been amputated uvula with slough over the soft palate, tonsillar regions and posterior pharyngeal wall. In the neck, there was crepitus over the anterior triangle with tenderness over the thyroid cartilage and submandibular region. The ear, nose and other systems were essentially normal.

Diagnosis of blunt throat injury to rule out foreign body was made. Plain radiograph of soft tissue neck revealed a well-defined coiled object of metallic density suggestive of a spring in the throat at the level of the 2 nd cervical vertebra. The FB was horizontal in orientation with the wider base anteriorly. The adjacent airway was normal in calibre but cervical lordosis was lost, suggestive of muscle spasm (Figure1,2).

The plastic cover of the touch was removed by the anaesthesiologist during endotracheal intubation while the spring of touch light cover was removed by the otorhinolaryngology via rigid pharyngoscopy after endotracheal intubation. Postoperatively, he had intravenous ceftriaxone and diclofenac potassium.

Patient did well following surgery but with moderate regurgitation of feeds through the nose. He was counselled on the need for close follow up but he had since defaulted.

\section{Discussion}

Children often ingest coins, toys, safety pins, buttons, crayons and ball caps, while older children and adults tend to ingest meat and bones. Mental ill patients and prisoners may ingest spoon, razor blade etc. $[8,10,13,14]$. Umana et al. reported 3-year-old boy that accidentally ingested disk battery and 13 month old child with disk battery in the oesophagus mimicking respiratory problem [16,17]. Ngim et al. reported 12 year old boy that accidentally ingested metallic detachable part of a padlock [18]. The index patient was not known mental ill person. He accidentally, swallowed the spring and plastic cover of a touch light held in his mouth as improvise for the headlamp of his motorcycle at night. This case is unique and highlights gross ignorance to safety rules, carelessness and probably poverty. The authors have not seen a similar predisposing factor/precipitating cause reported in the literature.

FB in the upper airway/digestive tract often pass through GIT and passed out with faeces without harm but when large in diameter or sharp FB may lodge at constriction and cause morbidity or life threatening complications or mortality $[8,14]$. The reported case, the spring of the touch light was impacted at level of hypo-pharynx with associated damage to the soft palate and posterior pharyngeal wall. $\mathrm{He}$ had features of acute upper GIT obstruction evidenced by dysphagia to solid foods, liquid and saliva, drooling of saliva with cough that was aggravated by lying down.

Impacted or dangerous FB is medical emergencies and prognosis depends largely on early diagnosis and appropriated management. Treatment options of ingested foreign body vary from 'watchful waiting' to endoscopic extraction, balloon catheter extraction, fluoroscopic removal and laparotomy [8-10,13-15]. Although our patient had no dyspnea, hoarseness, or stridor this foreign body was live threatening to our patient because an attempt to lie down made him to aspirate saliva and triggered coughing. Figure 1 and 2 revealed a spring-like FB in the pharynx.

CT-scan of the thorax/abdomen necessary to assess for complications such as perforations or abscess formation was not done because of financial constraints.

The unique FB- spring and its plastic cover were removed under general anaesthesia via rigid pharyngoscopy. There was regurgitation of fluid despite removal of FB. This was due to the traumatic amputation of the uvula and injury to the soft palate and posterior pharyngeal wall during ingestion of the FB.

The prognosis of ingested foreign body is usually good especially with early presentation, diagnosis, appropriate investigation, management and follow-up.

The occurrence of this type of foreign body is preventable by public enlightenment. The public should be enlightened on the dangers of driving any vehicle including motorcycle, tricycle or bicycle without headlights especially at night. Law enforcement agencies should make 
Citation: Abiola Grace Adekanye, Oboko OO, Ntuen UA, Olusijibomi AA, Iraskeb KJ et al. (2015) Unique Foreign Body of the Pharynx- Touch

Page 3 of 3

sure all vehicles, and any form of cycles are regularly inspected and anyone found guilty should be punished.

\section{Conclusion}

Ingested foreign body though commonly due to accident may in addition be due to neglect of safety rules, carelessness and ignorance. Poverty should not be an excuse for dangerous improvising. The authors recommend a deliberate public enlightenment on the dangers on driving without headlights.

\section{Consent}

Informed consent was obtained from the patient relative for the case report to be published.

\section{Conflict of Interests}

The authors declare that there is no conflict of interests regarding the publication of this paper.

\section{Author's contribution}

AG reviewed the case with JI at accident and emergency unit of our hospital on presentation. She was the surgeon that removed the spring with pharyngoscope under general anaesthesia. She wrote the case report and the literature review.

$\mathrm{OO}$ is the anaesthesiologist that during the course of intubation removed the plastic cover of the touch light.

AN was the consultant in charge of the patient. He read the manuscript and made necessary corrections.

JI was the registrar that clerked the patient at presentation. He was also the assistant surgeon.

$\mathrm{AO}$ was the radiologist that reported the radiographic films.

MO took care of the patient during night duty. He also read through the manuscript.

RB Read the manuscript and took part in the care of the patient while on admission.

\section{Acknowledgement}

The authors acknowledged the health workers such as Mrs. Mfon Awana (Ear, Nose and Throat nurse), medical record officers, portals and others that took part in treatment of the patient and also made this manuscript possible.

\section{References}

1. Gitlin DF, Caplan JP, Rogers MP, Avni-Barron O, Braun I, et al. (2007) Foreign-body ingestion in patients with personality disorders. Psychosomatics 48: 162-166.

2. Losanoff JE, Kjossev KT (2001) Gastrointestinal "crosses": an indication for surgery. J Clin Gastroenterol 33: 310-314.

3. Silverberg D, Menes T, Kim U (2006) Surgery for "body packers"--a 15year experience. World J Surg 30: 541-546.

4. Haidary A, Leider JS, Silbergleit R (2007) Unsuspected swallowing of a partial denture. AJNR Am J Neuroradiol 28: 1734-1735.

5. Munter D (2010) Foreign bodies. Gastrointestinal Foreign Bodies in Emergency Medicine. Medscape.

6. Smith MT, Wong RK (2007) Foreign bodies. Gastrointest Endosc Clin N Am 17: 361-382, vii.

7. Louie JP, Alpern ER, Windreich RM (2005) Witnessed and unwitnessed oesophageal foreign bodies in children. Pediatr Emerg Care 21: 582-585.

8. Okoye BCC, Erefan AZT (2001) Oesophageal foreign bodies in PortHarcourt, Nigeria. JOMIP 2: 62-64

9. Townsend CM, Beauchamp RD, Evers RM, Matton KI (2004) Sabiston Texbook of surgery, Elsevier Saunders.

10. Okoye IJ, Imo AO, Okwulehie V (2005) Radiologic management of impacted coin in the oesophagus--a case report. Niger J Clin Pract 8: 56-59.

11. Walner DL, Ouanounou S, Donnelly LF, Cotton RT (1999) Utility of radiographs in the evaluation of paediatric upper airway obstruction. Ann Otol Rhinol Laryngol 108: 378-383.

12. Wunsch R, Zieger B, Darge K, Wunsch C (1999) [Foreign body ingestion]. Radiologe 39: 472-477.

13. Ahmed BM, Dogo D, Abubakar Y (2001) Pharyngo-oesophageal foreign bodies in Maduguri. Nig J Surg Res 3: 62-65.

14. Frossard JL, de Peyer R (2011) An unusual digestive foreign body. Case Rep Gastroenterol 5: 201-205.

15. FEDER BH, MYERS GG (1953) Swallowed foreign bodies. Calif Med 79: 293-296.

16. Umana AN, Offiong ME, Ewa AU (2011) Foreign body (disk battery) in oesophagus mimicking respiratory problem in 13 month old babydelayed diagnosis. Journal of Medicine and Medicine Science 2: 714-717.

17. Umana AN, Offiong ME, Kuni J (2012) Esophgopleural Fistula in a 3 year old child following disk battery ingestion. The Internet Journal of Otorhinolaryngology: 1528-8420.

18. Ngim O, Adams L, Ikpeme A (2013) Unusual foreign body swallowed while asleep: Lessons to learn- a case report. Internet Journal of surgery 29:1. 